\title{
Residents of highly walkable neighbourhoods in Canadian urban areas do substantially more physical activity: a cross-sectional analysis
}

\author{
Justin Thielman MSc, Heather Manson MD MHSc, Maria Chiu PhD, Ray Copes MD MSc, \\ Laura C. Rosella PhD
}

\section{Abstract}

Background: Research has shown that neighbourhood walkability is associated with small differences in physical activity; however, the health impacts of these small differences have been questioned. We examined the size of the association of walkability with accelerometer-measured physical activity in a large, national-level Canadian population, and compared results to physical activity levels recommended in international guidelines. Our primary objective was to investigate the direction and size of the differences in physical activity that were related to walkability, and whether these differences depended on age.

Methods: Participants were included from among respondents to the 2007-2011 Canadian Health Measures Surveys who lived in urban areas and were aged 6-79 years. The Canadian Health Measures Surveys are ongoing cross-sectional surveys of a Canada-wide population. Respondents were divided into quintiles based on Street Smart Walk Score® values of their census dissemination areas. For all respondents and age subgroups, we used covariate-adjusted generalized linear models to estimate differences between quintiles in accelerometer-measured moderate-to-vigorous physical activity (MVPA) and sedentary time.

Results: We included 7180 respondents. Differences in participant MVPA between highest and lowest Street Smart Walk Score quintiles were $3.2(95 \%$ confidence interval $[\mathrm{Cl}]-3.2$ to 9.6$)$ minutes/day for ages $6-11$ years, $11.4(95 \% \mathrm{Cl} 5.3$ to 17.4$)$ minutes/day for ages $12-17$ years, $9.9(95 \% \mathrm{Cl} 2.4$ to 17.4$)$ minutes/day for ages $18-29$ years, 14.9 (95\% Cl 10.2 to 19.6) minutes/day for ages $30-44$ years, $11.5(95 \% \mathrm{Cl} 6.7$ to 16.3$)$ minutes/day for ages $45-64$ years and 6.9 (95\% Cl 3.1 to 10.8$)$ minutes/day for ages $65-79$ years. There were no significant differences in sedentary time in any age group.

Interpretation: In all groups except the youngest, participants in the most walkable areas did significantly more MVPA than those in the least walkable areas. For several age groups, this difference was approximately one-half to two-thirds of the amount recommended in guidelines for physical activity. Substantially higher MVPA levels suggest that residents of highly walkable areas may have greater health benefits.

$\mathrm{P}$ hysical inactivity is a widespread problem, with serious negative health consequences. ${ }^{1}$ International guidelines recommend adults do at least 150 minutes of moderateto-vigorous physical activity (MVPA) per week and that children do at least 60 minutes of MVPA per day. ${ }^{2,3}$ Recent research has shown most Canadians do not meet these guidelines., ${ }^{4,5}$ Public health professionals have increasingly focused on improving neighbourhood walkability as a potential means of increasing physical activity. ${ }^{6,7}$ Walkable neighbourhoods are those with a variety of destinations in close proximity, well-connected streets and adequate green space. ${ }^{8}$ If walkability influences physical activity behaviours, there may be far-reaching health implications across a broad population.

Concerns have arisen that walkability's association with physical activity may be too small to have a meaningful impact on health. ${ }^{9-11}$ Research shows, in addition to frequency and duration, higher intensities of physical activity produce greater health gains; hence, the guidelines' focus on minimum MVPA levels. ${ }^{12,13}$
Research also shows consistent positive associations between walkability and active transport. ${ }^{14,15}$ As active transport is classified as MVPA, ${ }^{16}$ positive associations between walkability and MVPA can be anticipated. Additionally, sedentary time, defined as waking time spent at an intensity below light physical activity, ${ }^{17}$ may have health consequences independent of MVPA. ${ }^{18}$ Furthermore, walkability may have associations with sedentary time unique from its associations with MVPA; for instance, in less walkable environments people may be more likely to use sedentary modes of transportation such as driving. ${ }^{16,19}$

\section{Competing interests: None declared.}

This article has been peer reviewed.

Correspondence to: Justin Thielman, justin.thielman @ oahpp.ca

CMAJ Open 2016. DOI:10.9778/cmajo.20160068 
Considering international guidelines, we aimed to investigate whether differences in physical activity related to walkability are large enough to have a meaningful impact on health. We also considered that the mixed results reported in previous studies may be due to methodological issues such as small sample sizes, subjective measures of physical activity and differential associations in various age groups (i.e., effect modification by age). 9,15,20,21 Therefore, we attempted to answer the following primary research question in a large Canada-wide sample: What are the sizes of associations between walkability and objectively measured MVPA and how does age modify these associations? We also sought to answer the following secondary research question related to sedentary time: What are the magnitudes of associations between walkability and sedentary time, and how does age modify these associations?

\section{Methods}

\section{Study design}

We used the Canadian Health Measures Survey for the periods March 2007-February 2009 and August 2009-November 2011. We used the first 2 cycles of this national-level, cross-sectional survey that collected both self-reported and direct measures of Canadians' health and health determinants. ${ }^{22,23}$ It used a 3-stage stratified sampling design to obtain a sample representative of about $96 \%$ of the population of Canada (people in institutions, full-time members of the Canadian Armed Forces, and people living in reserves, other Aboriginal settlements or certain remote areas were excluded). Additional information on this survey design is available from Statistics Canada. ${ }^{22,23}$

\section{Setting}

The Canadian Health Measures Survey included a questionnaire conducted in person at respondents' households using computerassisted interviewing, followed by visits to nearby mobile examination centres where direct measures were taken, followed by collection of physical activity monitor data over a 7-day period.

\section{Population}

Respondents of all ages (except those in wheelchairs) were asked to wear activity monitors during waking hours for 7 days for data collection. ${ }^{22,23}$ A minimum of 4 valid days (days with 10 or more hr of wear time) of activity monitor data were needed for accurate measures of average physical activity. The Canadian Health Measures Survey reweighted the subsample of respondents with at least 4 valid days to improve representativeness. We further restricted the activity monitor subsample to those residing in urban areas (defined by Statistics Canada as contiguously built up areas with at least 400 people $/ \mathrm{km}^{2}$ and total populations of at least 1000). ${ }^{24} \mathrm{We}$ also excluded respondents with missing data for walkability and key sociodemographic characteristics.

\section{Source of exposure data: walkability}

The Street Smart Walk Score® (hereinafter referred to as Walk Score) metric was our neighbourhood walkability indicator. ${ }^{25}$ This metric has been validated, ${ }^{26-28}$ and previous studies have identified associations with outcomes such as utilitarian walking, obesity and hypertension. ${ }^{29-31}$ Walk Score values were calculated for specific locations based on the number, variety and proximity of various amenities (e.g., restaurants/bars, parks, schools), and connectivity of surrounding streets. Values ranged from 0 to 100 , with higher values indicating greater amenity density, more connected streets and, therefore, a more walkable location. Additional information on Walk Score methodology can be found at www.walkscore.com.

We used population-weighted latitude/longitude coordinates of census dissemination areas assigned to survey respondents as proxies for primary residences. Dissemination areas are designed to cover areas with 400-700 people. ${ }^{32}$ Therefore, in urban areas, dissemination areas are small enough to reasonably correspond with residential location. In 2014, we sent these latitude/longitude coordinates to the Walk Score developers, who provided Walk Score values for each coordinate. Data files for the Canadian Health Measures Survey included postal codes for respondents but not dissemination areas; therefore, we matched dissemination areas (and their calculated Walk Scores) to the survey respondents' postal codes using Statistics Canada's Postal Code Conversion File. ${ }^{33}$

\section{Source of outcome data: moderate-to-vigorous physical activity and sedentary time}

Respondents wore activity monitors on adjustable belts. These monitors were designed to capture movement along 3 vectors (triaxial) to allow acquisition of most types of physical activity as counts. $^{22}$ Moderate-to-vigorous physical activity (MVPA, $\mathrm{min} / \mathrm{d}$ ) was calculated as the number of minutes of daily wear time recorded at or above 1500 counts/minute for respondents aged 6-19 years, and at or above 1535 counts/minute for respondents aged 20-79 years. ${ }^{34,35}$ These cut points are roughly equivalent to physical activity intensity above 3 metabolic equivalents. Metabolic equivalent values are defined as the ratio of the body's metabolic rate while doing a particular exercise to its metabolic rate while at rest. ${ }^{16}$ For example, if the body's metabolic rate while walking is 4 times its metabolic rate while at rest, walking has a metabolic equivalent value of 4 . For all ages, sedentary time $(\mathrm{min} / \mathrm{d})$ was calculated as the number of minutes of wear time recorded above 0 and below 100 counts/minute. ${ }^{36}$ These cut points are roughly equivalent to intensities between 0 and 2 metabolic equivalents. Nonwear time was considered to be 60 or more consecutive minutes with 0 counts (allowing 1-2 min of counts between 0 and 100).,

\section{Statistical analysis}

We divided respondents into quintiles according to Street Smart Walk Score values assigned to them. For each Walk Score quintile and for the total study population, we calculated means and proportions of important sociodemographic characteristics. We built generalized linear models of associations between walkability and MVPA, both unadjusted and adjusted for important confounders, and used generalized estimating equations to account for clustering of multiple respondents within single dissemination areas. To test effect modification by age, we tested interactions between age group 
and Walk Score quintile in the adjusted models. We built models for all respondents and the following age strata: 6-11, $12-17,18-29,30-44,45-64$ and $65-79$ years. These strata reflected our estimation of the following life stages: child, youth, young adult, early-middle-aged adult, late-middleaged adult and older retired/semiretired adult. We built a similar set of models for associations between Walk Score quintiles and sedentary time.

Covariate-adjusted models for respondents overall included the following variables, anticipated to be the most important confounders based on previous research: ${ }^{4,5,37-40}$ age category, sex, visible minority status (defined as nonwhite race), immigration to Canada in the past 10 years, postsecondary graduate in the household, household income quintile, number of children under 12 in the household, did respondents work or attend school and activity monitor wear time. The covariateadjusted models for age subgroups were adjusted for the same variables, except age category.

For all estimates, we accounted for the complex survey design using activity monitor subsample survey weights provided by Statistics Canada. To obtain more accurate variance estimates, we normalized survey weights by dividing each respondent's survey weight by the mean weight for all respondents in our study. We used $95 \%$ confidence intervals (CI) to determine statistical significance for all estimates. We used SAS version 9.4 (SAS Institute) for all analyses.

\section{Ethics approval}

After reviewing our study protocol, the Ethics Review Board of Public Health Ontario granted ethics approval, and Statistics Canada's Research Data Centre granted access to the Canadian Health Measures Survey.

\section{Results}

\section{Population}

The percentage of people contacted who completed the household questionnaire, visited the mobile examination centre and returned valid activity monitor data was $42.1 \%$ averaged across both Canadian Health Measures Survey cycles; however, these respondents were reweighted to be nationally representative. ${ }^{22,23}$ A flow diagram of participant response is in Appendix 1 (available at www.cmajopen.ca/content/4/4/E720/ suppl/DC1). Figure 1 provides a flow diagram of our study's

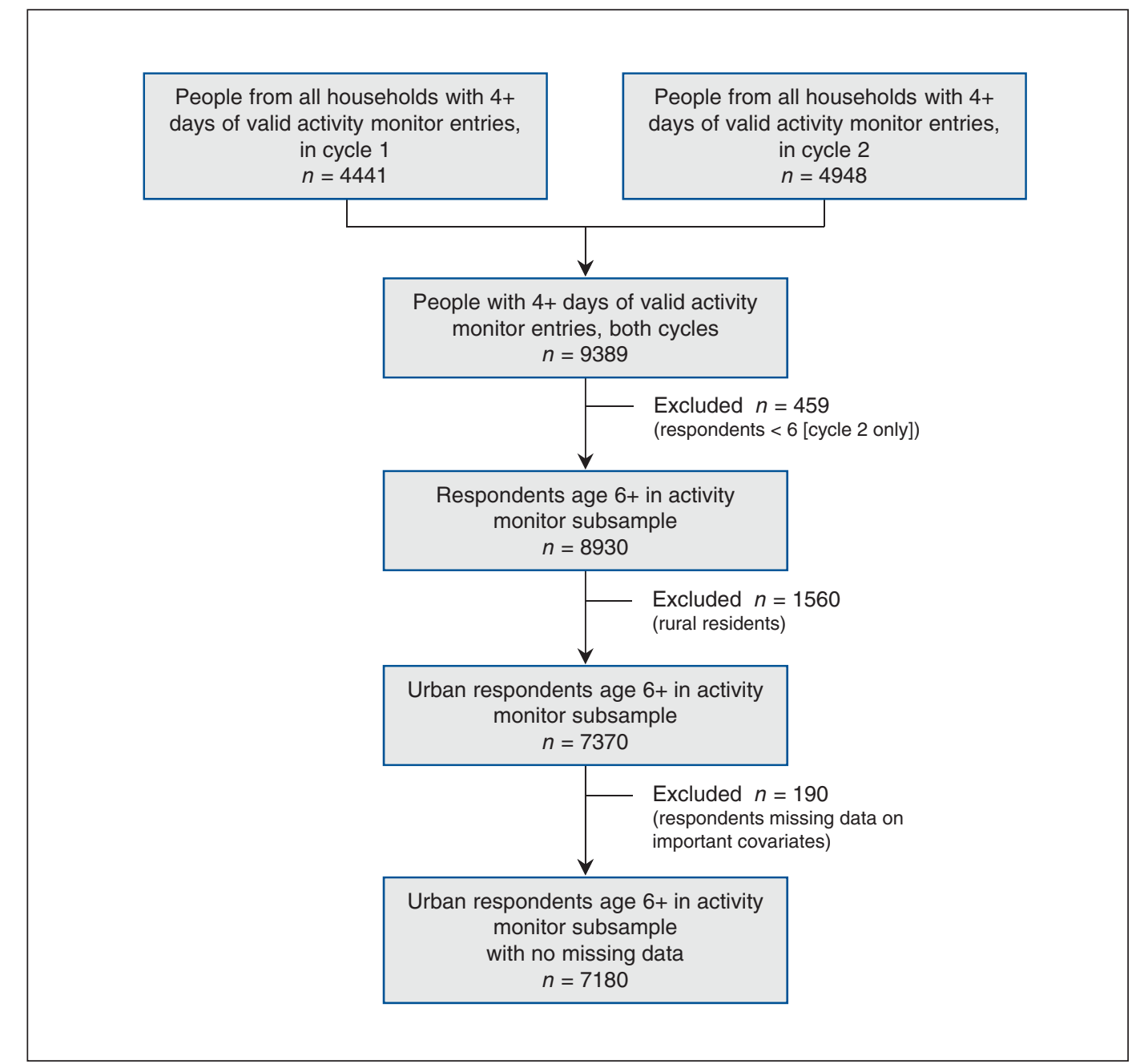

Figure 1: Flow diagram of Canadian Health Measures Survey respondents eligible for the walkability study. 


\section{Table 1: Study population characteristics (Canada-wide): overall and by Street Smart Walk Score quintile}

\section{Street Smart Walk Score quintile}

\begin{tabular}{|c|c|c|c|c|c|c|}
\hline \multirow[b]{2}{*}{ Variable } & \multirow[b]{2}{*}{$\begin{array}{l}\text { Total no. of } \\
\text { respondents for } \\
\text { all quintiles (\%) }\end{array}$} & \multicolumn{5}{|c|}{ Street Smart Walk Score quintile } \\
\hline & & $\begin{array}{c}\text { No. of } \\
\text { respondents } \\
(\%) \ddagger \\
\text { in Q1, 0-22 }\end{array}$ & $\begin{array}{c}\text { No. of } \\
\text { respondents } \\
(\%) \ddagger \\
\text { in Q2, 23-40 }\end{array}$ & $\begin{array}{c}\text { No. of } \\
\text { respondents } \\
(\%) \ddagger \\
\text { in Q3, 41-58 }\end{array}$ & $\begin{array}{c}\text { No. of } \\
\text { respondents } \\
(\%) \ddagger \\
\text { in Q4, 59-79 }\end{array}$ & $\begin{array}{c}\text { No. of } \\
\text { respondents } \\
(\%) \ddagger \\
\text { in Q5, 80-100 }\end{array}$ \\
\hline No. of respondents (weighted) & 7180 & 1388 & 1390 & 1496 & 1442 & 1464 \\
\hline \multicolumn{7}{|l|}{ Age category, yr } \\
\hline $6-11$ & $533(7.4)$ & $135(9.7)$ & $118(8.5)$ & $116(7.8)$ & $92(6.4)$ & $72(4.9)$ \\
\hline $12-17$ & $617(8.6)$ & $116(8.4)$ & $151(10.9)$ & $143(9.6)$ & $119(8.3)$ & $89(6.1)$ \\
\hline $18-29$ & $1335(18.6)$ & $226(16.3)$ & $280(20.1)$ & $250(16.7)$ & $273(18.9)$ & 306 (20.9) \\
\hline $30-44$ & $1815(25.3)$ & $362(26.1)$ & $305(21.9)$ & $368(24.6)$ & $317(22.0)$ & $462(31.6)$ \\
\hline $45-64$ & $2172(30.3)$ & $432(31.1)$ & $423(30.5)$ & $452(30.2)$ & $454(31.5)$ & $410(28.0)$ \\
\hline $65-79$ & $707(9.8)$ & $117(8.4)$ & $113(8.1)$ & $166(11.1)$ & $186(12.9)$ & $125(8.5)$ \\
\hline \multicolumn{7}{|l|}{ Sex } \\
\hline Male & $3540(49.3)$ & $689(49.6)$ & $651(46.8)$ & $705(47.1)$ & $738(51.2)$ & $757(51.7)$ \\
\hline Female & $3639(50.7)$ & $699(50.4)$ & $739(53.2)$ & $791(52.9)$ & $703(48.8)$ & 707 (48.3) \\
\hline \multicolumn{7}{|l|}{ Visible minority status } \\
\hline Visible minority & $1625(22.6)$ & $184(13.2)$ & $256(18.4)$ & $376(25.1)$ & $415(28.8)$ & $393(26.9)$ \\
\hline Not a visible minority & $5555(77.4)$ & $1204(86.7)$ & $1133(81.6)$ & $1120(74.9)$ & $1026(71.2)$ & $1070(73.1)$ \\
\hline \multicolumn{7}{|l|}{ Immigrated to Canada in previous $10 \mathrm{yr}$} \\
\hline Yes & $715(10.0)$ & $74(5.3)$ & $64(4.6)$ & $182(12.1)$ & $143(9.9)$ & $251(17.2)$ \\
\hline No & $6465(90.0)$ & $1314(94.7)$ & $1325(95.4)$ & $1314(87.8)$ & $1299(90.1)$ & $1212(82.8)$ \\
\hline \multicolumn{7}{|l|}{ Postsecondary graduate ${ }^{*}$ in household } \\
\hline Yes & $5747(80.0)$ & $1157(83.4)$ & $1112(80.0)$ & $1172(78.3)$ & $1073(74.5)$ & $1232(84.2)$ \\
\hline No & $1432(20.0)$ & $231(16.6)$ & $277(20.0)$ & $324(21.7)$ & $368(25.5)$ & $231(15.8)$ \\
\hline \multicolumn{7}{|l|}{ Household income, Can\$† } \\
\hline $0-36000$ & $1416(19.7)$ & $163(11.7)$ & $196(14.1)$ & $239(16.0)$ & $397(27.5)$ & $421(28.8)$ \\
\hline $36500-59500$ & $1370(19.1)$ & $221(15.9)$ & $231(16.6)$ & $324(21.7)$ & $295(20.5)$ & $298(20.4)$ \\
\hline $60000-79500$ & $1175(16.4)$ & $248(17.9)$ & $216(15.5)$ & $254(17.0)$ & $232(16.1)$ & $225(15.4)$ \\
\hline $80000-114000$ & $1755(24.4)$ & $426(30.7)$ & $417(30.0)$ & $357(23.9)$ & $292(20.3)$ & $265(18.1)$ \\
\hline$>114500$ & $1463(20.4)$ & $331(23.8)$ & $330(23.7)$ & $322(21.5)$ & $225(15.6)$ & $255(17.4)$ \\
\hline \multicolumn{7}{|l|}{ No. of persons $<12 \mathrm{yr}$ of age in household } \\
\hline 0 & $4811(67.0)$ & $854(61.5)$ & $907(65.3)$ & $984(65.8)$ & $1036(71.8)$ & $1030(70.4)$ \\
\hline 1 & $1203(16.8)$ & $218(15.7)$ & $246(17.7)$ & $226(15.1)$ & $217(15.0)$ & $296(20.2)$ \\
\hline 2 or more & $1166(16.2)$ & $317(22.8)$ & $236(17.0)$ & $286(19.1)$ & $189(13.1)$ & $138(9.4)$ \\
\hline \multicolumn{7}{|l|}{ Works or attends school } \\
\hline Yes & $6075(84.6)$ & $1176(84.7)$ & $1230(88.5)$ & $1220(81.6)$ & $1155(80.1)$ & $1294(88.4)$ \\
\hline No & $962(13.4)$ & $191(13.7)$ & $138(9.9)$ & $247(16.5)$ & $246(17.1)$ & $141(9.6)$ \\
\hline Missing & 143 & 21 & 22 & 29 & 41 & 29 \\
\hline \multicolumn{7}{|l|}{ Has difficulty walking } \\
\hline Yes & $124(1.7)$ & $24(1.7)$ & $23(1.7)$ & $27(1.8)$ & $36(2.5)$ & $15(1.0)$ \\
\hline No & 7055 (98.3) & 1364 (98.3) & $1367(98.3)$ & 1469 (98.2) & $1406(97.5)$ & $1449(99.0)$ \\
\hline Activity monitor wear time, $\mathrm{min} / \mathrm{d} ;$ mean $\pm \mathrm{SD}$ & $835.1 \pm 77.1$ & $834.5 \pm 68.5$ & $840.0 \pm 72.8$ & $842.1 \pm 80.7$ & $833.7 \pm 80.4$ & $825.3 \pm 81.9$ \\
\hline \multicolumn{7}{|c|}{ 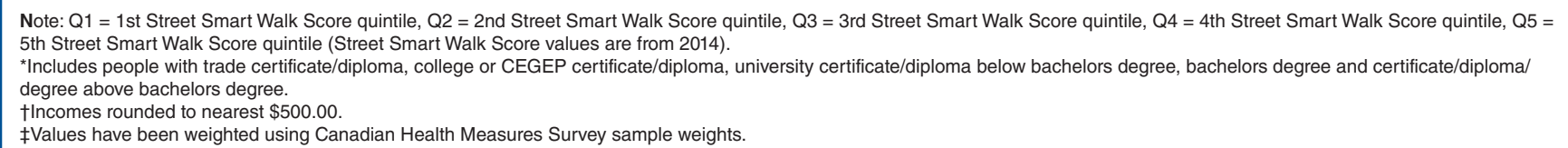 } \\
\hline
\end{tabular}


exclusions. We included 7180 participants in our final sample population.

Table 1 shows sociodemographic characteristics and activity monitor wear time for the overall sample population and each Walk Score quintile. Our sample population had more postsecondary graduates than the full Canadian Health Measures Survey sample population aged 6-79 years old, a difference of 5.4 percentage points. Differences for all other sociodemographic characteristics in Table 1 were less than 3 percentage points. Sociodemographic characteristics of the full Canadian Health Measures Survey sample population are available in Appendix 2 (available at www.cmajopen.ca/content/ 4/4/E720/suppl/DC1). Figure 2 shows MVPA (min/d) and sedentary time for each age category.

Table 2 shows which population characteristics had statistically significant differences between Walk Score quintiles. Areas with higher Walk Score quintiles had greater proportions of households with low incomes and smaller proportions of households with high incomes. This is consistent with earlier research showing that lower-income households tend to be in more developed areas, which subsequently have greater walking access to neighbourhood amenities. ${ }^{41,42}$

\section{MVPA}

In the unadjusted analysis of all study participants, people living in the highest Walk Score quintile did significantly more MVPA than people in the lowest quintile. Most unadjusted analyses of age subgroups showed significant positive associations when comparing highest to lowest quintiles (Table 3). In the covariate-adjusted analysis of all study participants, the highest quintile did an average of 11.8 minutes more MVPA per day (95\% CI 9.1 to 14.5 ) than the lowest quintile. There was a statistically significant $(p<0.05)$ interaction between the highest quintile and all age groups, except for those aged $18-29$ years $(p=0.07)$ and 65 years and older $(p=0.14)$; therefore, we proceeded with the subgroup analysis. Subgroup analysis by age showed significant differences between highest and lowest quintiles in all but the youngest age group (Table 3 and Figure 3). MVPA differences between the 2nd-4th Walk
Score quintiles and the lowest quintile were smaller, and most were not significant.

\section{Sedentary time}

Covariate-adjusted associations between Walk Score quintiles and sedentary time were not significant when comparing all higher quintiles with the lowest. There were no statistically significant interactions between age group and any Walk Score quintile. Unadjusted and adjusted differences in sedentary time between quintiles are available in Appendix 3 (available at www.cmajopen.ca/content/4/4/E720/suppl/DC1).

\section{Discussion}

Analyzing all respondents together, people living in the most walkable neighbourhoods engaged in significantly more objectively measured MVPA than people in the least walkable neighbourhoods. Differences for the highest quintile were markedly larger than those for the 2nd-4th quintiles, a finding consistent with other walkability research. ${ }^{43}$ In the subgroup analysis, adults aged 30-44 years showed the strongest association, with the highest quintile doing almost 15 minutes per day more MVPA, on average. This is equivalent to 105 minutes of MVPA per week, or over two-thirds of the weekly recommendation of 150 minutes per week for adults. ${ }^{2,3}$ Differences for adults aged 18-29 years and 45-64 years were also large, with the highest quintile doing 70-80 minutes per week more MVPA, which is about half the recommendation for adults. Children aged 6-11 years were the only subgroup without a statistically significant difference in MVPA between quintiles. Perhaps this is because characteristics captured by the Walk Score metric, such as amenity density and street connectivity, do not influence the types of activity children engage in (e.g., active play).

Our study is most comparable to studies assessing MVPA time using accelerometers, because self-reported measures can differ substantially because of poor recall, social desirability and other biases. ${ }^{44}$ Accelerometer use increases the resource requirements and participant burden of studies; therefore, most studies using accelerometers have sample populations under 400, which limits their power to detect associations. ${ }^{9,45}$
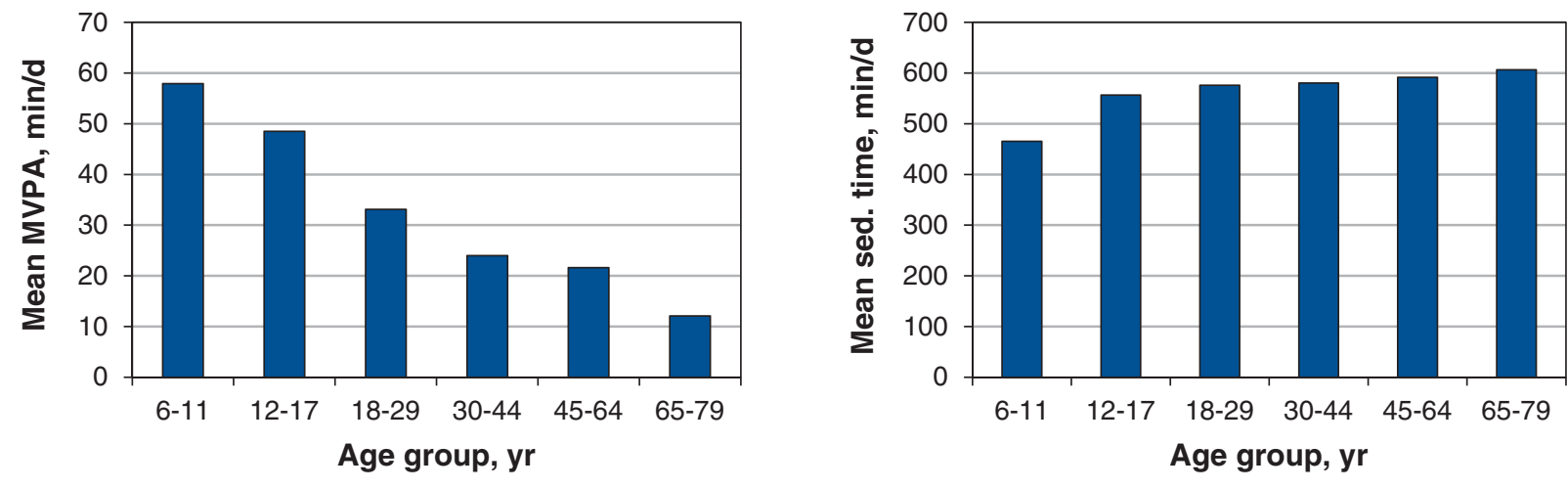

Figure 2: Mean moderate-to-vigorous activity (MVPA; $\mathrm{min} / \mathrm{d})$ and sedentary time, by age group $(n=7180)$. 


\section{Table 2: Differences in population characteristics across Street Smart Walk Score quintiles}

\begin{tabular}{|lc}
\hline Population characteristic & $p^{*}$ \\
\hline Age category, yr & $<0.001$ \\
\hline $6-11$ & $<0.001$ \\
\hline $12-17$ & 0.01 \\
\hline $18-29$ & $<0.001$ \\
\hline $30-44$ & 0.5 \\
\hline $45-64$ & $<0.001$ \\
\hline $65-79$ & \\
\hline Sex & 0.2 \\
\hline Male & 0.2 \\
\hline Female & \\
\hline Visible minority status & $<0.001$ \\
\hline Visible minority & $<0.001$ \\
\hline Not a visible minority & \\
\hline Immigrated to Canada in previous 10 yr & $<0.001$ \\
\hline Yes & 0.002 \\
\hline No & $<0.001$ \\
\hline Postsecondary graduate† in household & \\
\hline Yes & \\
\hline No & \\
\hline
\end{tabular}

Household income, Can\$‡

$\begin{array}{lc}0-36000 & <0.001 \\ 36500-59500 & <0.001 \\ 60000-79500 & 0.4 \\ 80000-114000 & <0.001 \\ \geq 114500 & <0.001\end{array}$

No. of persons $<12 \mathrm{yr}$ of age in household

\begin{tabular}{|cc|}
0 & 0.005 \\
\hline 2 or more & 0.002 \\
\hline
\end{tabular}

\section{Works or attends school}

\begin{tabular}{|lc|}
\hline Yes & 0.04 \\
\hline No & $<0.001$ \\
\hline Has difficulty walking & $<0.001$ \\
\hline Yes & 0.06 \\
\hline No & 1.0 \\
\hline Activity monitor wear time, $\mathrm{min} / \mathrm{d}$ & $<0.001$ \\
\hline
\end{tabular}

${ }^{*} p$ values are for $\chi^{2}$ goodness-of-fit tests across Street Smart Walk Score quintiles, except activity monitor wear time, where $p$ values are for 1-way ANOVA across quintiles. †Includes people with trade certificate/diploma, college or CEGEP certificate/diploma university certificate/diploma below bachelors degree, bachelors degree, certificate/ diploma/degree above bachelors degree.

flncomes rounded to nearest $\$ 500.00$.
Our findings are similar to 3 studies in the US that are among the largest studies that used objective MVPA measures in their respective age categories. In a study by Sallis and colleagues that involved 2199 adults aged 20-65 years, residents of highly walkable neighbourhoods did 5.8 minutes per day more MVPA than those in less walkable neighbourhoods. ${ }^{46}$ Carlson and colleagues' study involving 687 adults aged 65 years and older also identified a positive walkability-MVPA association. ${ }^{47}$ In a study involving 770 youth aged $11-15$ years, Norman and colleagues found that MVPA was associated with certain features of walkability, such as nearby parks and retail floor area ratio but not with an overall index of walkability. ${ }^{48}$

The studies by Sallis, Carlson, and Norman and their respective colleagues were confined to 1 or 2 major American cities and may not be generalizable to smaller municipalities or other countries. Two recent studies in Canada analyzed national-level populations using the Walk Score metric to assess walkability. ${ }^{31,49}$ Thielman and colleagues found positive associations between walkability and self-reported total physical activity among people aged 30-64 years, but they did not find associations among those aged $12-17,18-29$ or 65 years and older. ${ }^{31}$ Hajna and colleagues examined adult respondents to the Canadian Health Measures Survey cycle 1, a subset of our study population, but they did not find significant associations between walkability and objectively measured step counts. ${ }^{49}$ Our positive results differ from these null findings, possibly because of the following: the majority of daily physical activity is light physical activity; therefore, studies that assessed "total physical activity" or "step counts" captured mostly light physical activity. ${ }^{4,5}$ Common light physical activities include light household cleaning and walking around workplaces, ${ }^{16}$ which are not expected to be associated with neighbourhood walkability. The physical activities most commonly associated with walkability are transport walking and cycling, which are MVPA. ${ }^{14-16}$ Therefore, walkability may be associated with MVPA (e.g., through active transport) but not with light physical activity, and our study isolated the association with MVPA.

Our null findings on walkability and objectively measured sedentary time add to a smaller body of literature in this area, most of which assessed sedentary time using self reporting. ${ }^{19}$ A systematic review of studies involving adults found only $28 \%$ of the comparisons between environmental attributes and sedentary time were significant in the expected direction. ${ }^{19}$ A study in Australia $(n=1072)$ of self-reported television viewing time by older adults identified a significant positive association with only 1 of 7 perceived environmental attributes; ${ }^{50}$ however, a large $(n=3105)$ British study involving youth aged 11-12 years found greater walkability or cycleability was associated with less self-reported sedentary time. ${ }^{51}$

Our study's large national-level study sample population and objective measures are major strengths; however, some limitations must be considered. Although our analysis accounts for differences in many sociodemographic covariates and accelerometer wear time, it does not include variables such as neighbourhood safety, weather or self-selection of participants into neighbourhoods amenable to their level of physical activity. There was also a time lag between assess- 


\section{OPEN}

Research

ment of MVPA and sedentary time, which occurred from 2007 to 2011, and assessment of neighbourhood walkability, which was done in 2014. However, as most built environ- ments do not change rapidly, ${ }^{52}$ we expected minimal misclassification into Walk Score quintiles. Additionally, there may have been selection bias if people who were less physically

\begin{tabular}{|c|c|c|c|c|}
\hline Age group, yr & $\begin{array}{l}\text { Quintile (Walk Score } \\
\text { range) }\end{array}$ & $\begin{array}{c}\text { MVPA, } \min / d ; \\
\text { weighted mean } \pm \text { SD }\end{array}$ & $\begin{array}{l}\text { Unadjusted difference } \\
\qquad(95 \% \mathrm{Cl})\end{array}$ & $\begin{array}{l}\text { Adjusted }{ }^{*} \text { difference } \\
\qquad(95 \% \mathrm{Cl})\end{array}$ \\
\hline \multirow[t]{5}{*}{ All participants } & Q5 (80-100) & $35.1 \pm 27.9$ & 9.7 (6.7 to 12.8$)$ & $11.8(9.1$ to 14.5$) \dagger$ \\
\hline & Q4 (59-79) & $25.9 \pm 23.1$ & 0.5 (-2.2 to 3.3$)$ & $2.2(-0.3$ to 4.7$) \dagger$ \\
\hline & Q3 (41-58) & $28.0 \pm 26.5$ & 2.6 (-0.9 to 6.2$)$ & $3.6(0.5$ to 6.7$) \dagger$ \\
\hline & Q2 (23-40) & $27.5 \pm 25.6$ & $2.2(-0.5$ to 4.9$)$ & $1.5(-1.0$ to 4.0$) \dagger$ \\
\hline & Q1 (0-22) & $25.3 \pm 21.9$ & Ref. & Ref.† \\
\hline \multirow[t]{5}{*}{$6-11$} & Q5 (80-100) & $56.8 \pm 15.3$ & $-0.1(-6.7$ to 6.5$)$ & $3.2(-3.2$ to 9.6$)$ \\
\hline & Q4 (59-79) & $57.3 \pm 15.6$ & $0.4(-5.4$ to 6.3$)$ & $1.5(-4.5$ to 7.5$)$ \\
\hline & Q3 (41-58) & $58.6 \pm 18.0$ & $1.6(-4.7$ to 8.0$)$ & $3.2(-2.8$ to 9.2$)$ \\
\hline & Q2 (23-40) & $59.4 \pm 18.2$ & 2.5 (-3.9 to 8.8$)$ & $2.2(-3.6$ to 7.9$)$ \\
\hline & Q1 (0-22) & $56.9 \pm 15.8$ & Ref. & Ref. \\
\hline \multirow[t]{5}{*}{$12-17$} & Q5 (80-100) & $54.6 \pm 19.6$ & 10.5 (3.4 to 17.6$)$ & 11.4 (5.3 to 17.4$)$ \\
\hline & Q4 (59-79) & $46.4 \pm 18.2$ & 2.3 (-3.9 to 8.4$)$ & $3.5(-2.2$ to 9.1$)$ \\
\hline & Q3 (41-58) & $49.9 \pm 22.5$ & $5.8(-0.8$ to 12.3$)$ & $6.5(0.8$ to 12.2$)$ \\
\hline & Q2 (23-40) & $48.5 \pm 25.4$ & $4.4(-2.3$ to 11.0$)$ & $6.9(0.7$ to 13.0$)$ \\
\hline & Q1 (0-22) & $44.1 \pm 15.9$ & Ref. & Ref. \\
\hline \multirow[t]{5}{*}{$18-29$} & Q5 (80-100) & $40.8 \pm 26.8$ & 9.9 (1.0 to 18.8$)$ & $9.9(2.4$ to 17.4$)$ \\
\hline & Q4 (59-79) & $31.1 \pm 28.5$ & $0.2(-9.4$ to 9.9$)$ & $-1.4(-9.7$ to 7.0$)$ \\
\hline & Q3 (41-58) & $34.6 \pm 38.7$ & $3.8(-11.6$ to 19.2$)$ & $3.1(-9.0$ to 15.1$)$ \\
\hline & Q2 (23-40) & $27.0 \pm 27.6$ & $-3.9(-12.8$ to 5.0$)$ & $-5.6(-13.5$ to 2.3$)$ \\
\hline & Q1 (0-22) & $30.9 \pm 29.0$ & Ref. & Ref. \\
\hline \multirow[t]{5}{*}{$30-44$} & Q5 (80-100) & $34.3 \pm 27.9$ & 16.9 (11.5 to 22.3 ) & $14.9(10.2$ to 19.6$)$ \\
\hline & Q4 (59-79) & $21.4 \pm 17.0$ & $4.0(-0.3$ to 8.3$)$ & $3.1(-0.9$ to 7.0$)$ \\
\hline & Q3 (41-58) & $21.7 \pm 19.3$ & $4.3(-0.4$ to 9.0$)$ & $3.7(-0.3$ to 7.8$)$ \\
\hline & Q2 (23-40) & $21.8 \pm 15.5$ & $4.4(0.5$ to 8.3$)$ & $3.4(0.0$ to 6.8$)$ \\
\hline & Q1 (0-22) & $17.4 \pm 15.2$ & Ref. & Ref. \\
\hline \multirow[t]{5}{*}{$45-64$} & Q5 (80-100) & $29.4 \pm 35.0$ & 11.0 (5.9 to 16.1$)$ & 11.5 (6.7 to 16.3$)$ \\
\hline & Q4 (59-79) & $19.3 \pm 20.8$ & $0.9(-2.5$ to 4.3$)$ & $1.0(-2.7$ to 4.7$)$ \\
\hline & Q3 (41-58) & $20.8 \pm 23.3$ & $2.4(-1.5$ to 6.3$)$ & $2.9(-0.9$ to 6.7$)$ \\
\hline & Q2 (23-40) & $20.5 \pm 27.7$ & $2.1(-2.0$ to 6.3$)$ & $1.7(-2.2$ to 5.6$)$ \\
\hline & Q1 (0-22) & $18.4 \pm 20.5$ & Ref. & Ref. \\
\hline \multirow[t]{5}{*}{$65-79$} & Q5 (80-100) & $16.1 \pm 13.3$ & 6.2 (2.2 to 10.2$)$ & 6.9 (3.1 to 10.8$)$ \\
\hline & Q4 (59-79) & $13.4 \pm 19.2$ & $3.5(-1.3$ to 8.4$)$ & $4.3(-0.1$ to 8.7$)$ \\
\hline & Q3 (41-58) & $11.1 \pm 15.3$ & $1.2(-2.5$ to 4.9$)$ & $1.2(-2.4$ to 4.8$)$ \\
\hline & Q2 (23-40) & $9.3 \pm 13.3$ & $-0.6(-4.1$ to 3.0$)$ & $-0.3(-3.7$ to 3.2$)$ \\
\hline & Q1 (0-22) & $9.9 \pm 10.7$ & Ref. & Ref. \\
\hline \multicolumn{5}{|c|}{$\begin{array}{l}\text { Note: } \mathrm{Cl}=\text { confidence interval, MVPA }=\text { moderate-to-vigorous physical activity, Q1 }=1 \text { st Street Smart Walk Score quintile, Q2 }=2 \text { nd Street Smart Walk Score quintile, Q3 = } \\
\text { 3rd Street Smart Walk Score quintile, Q4 = 4th Street Smart Walk Score quintile, Q5 }=5 \text { th Street Smart Walk Score quintile, Ref. = reference. Statistically significant } \\
\text { estimates at } p<0.05 \text { are in boldface type. } \\
\text { *All estimates adjusted for sex, visible minority status, immigration to Canada in the past } 10 \mathrm{yr} \text {, having a postsecondary graduate in the household, household income quintile } \\
\text { number of children under } 12 \text { in the household, whether respondents work or attend school, whether respondents have difficulty walking and activity monitor wear time. } \\
\text { †Analyses of all respondents also adjusted for age category. Street Smart Walk Score values are from 2014. Remaining variables from the } 2007 \text { to } 2011 \text { Canadian Health } \\
\text { Measures Survey. }\end{array}$} \\
\hline
\end{tabular}




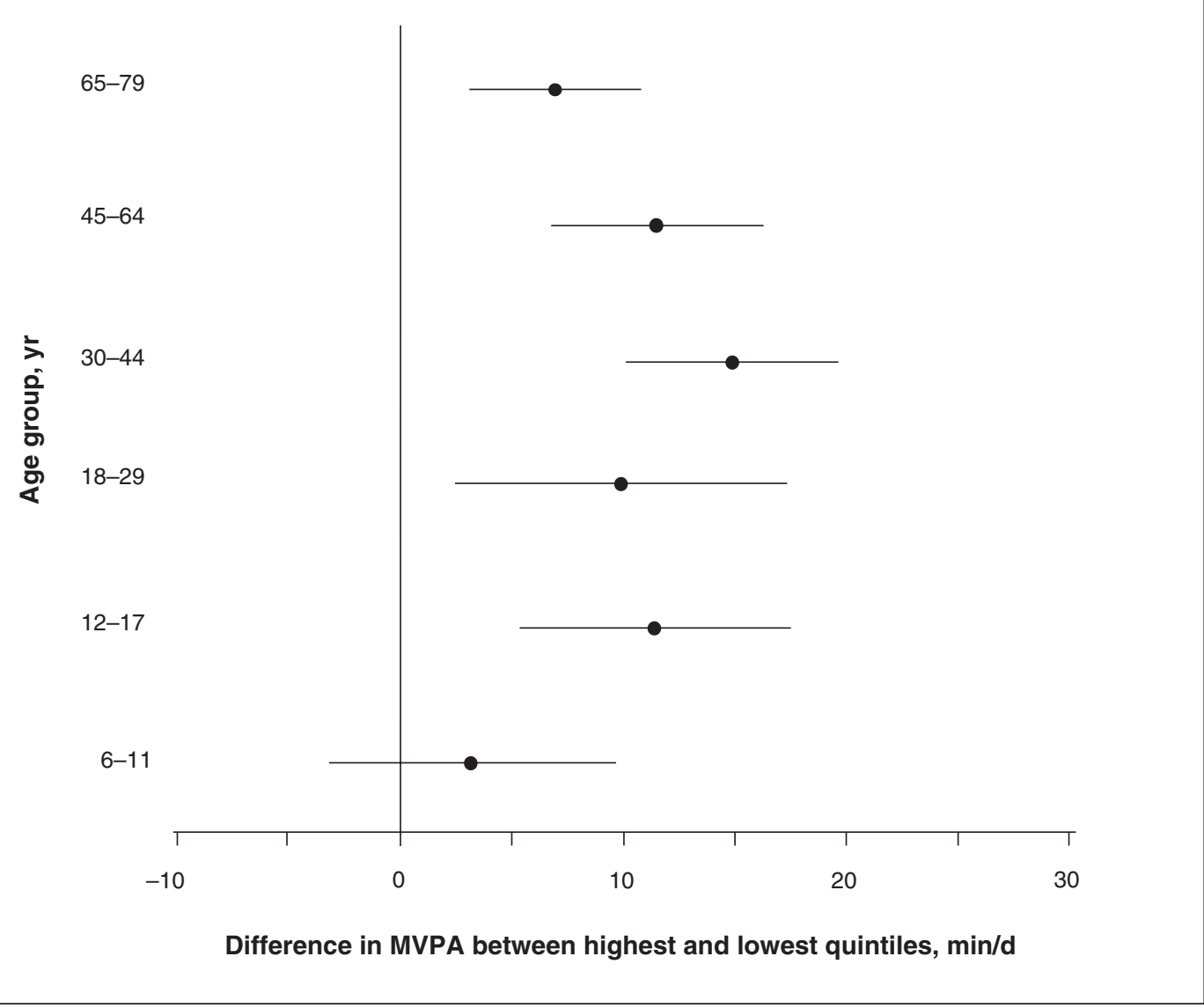

Figure 3: Covariate-adjusted difference in moderate-to-vigorous physical activity (MVPA; min/d) between highest and lowest Street Smart Walk Score quintiles, by age group.

active were less likely to return valid activity monitor data. Furthermore, the 4-7 day wear period may not be representative of typical activity levels for some people, and the minimum 10-hour wear protocol may have missed important activity information. Another limitation is the cross-sectional study design, which limits conclusions about the temporality of the associations assessed.

\section{Conclusion}

In all but the youngest age group, people living in the most walkable urban neighbourhoods did significantly more MVPA than people in the least walkable urban neighbourhoods. Furthermore, the higher MVPA in several age groups made up a substantial portion of the international physical activity guidelines, suggesting the higher MVPA levels in highly walkable areas can have a meaningful impact on risk of chronic disease. These findings add to a body of walkability research that has shown mixed results when examining MVPA and sedentary time, which may be due to methodologic issues in many of these studies. ${ }^{9,19}$ Future studies should aim to maintain the use of objective measures and large sample sizes, while using longitudinal designs that allow the temporality of this relationship to be examined. If such studies identify walkability-MVPA associations of a similar size as our study, this will suggest that improving walkability is a promising means of achieving meaningful increases in physical activity across a broad population.

\section{References}

1. The top 10 causes of death. Fact sheet $N^{\circ} 310$. Geneva: World Health Organization; 2014. Available: www.who.int/mediacentre/factsheets/fs $310 / \mathrm{en} /$ (accessed 2016 Feb. 23).

2. Global recommendations on physical activity for health. Geneva: World Health Organization; 2014. Available: www.who.int/dietphysicalactivity/factsheet_recommendations/en/ (accessed 2016 Feb. 24).

3. Canadian physical activity and sedentary behaviour guidelines: your plan to get active every day. Ottawa: Canadian Society of Exercise Physiology; 2012. Available: http://csep.ca/CMFiles/Guidelines//CSEP_Guidelines_Handbook.pdf (accessed 2016 Oct. 25)

4. Colley RC, Garriguet D, Janssen I, et al. Physical activity of Canadian children and youth: accelerometer results from the 2007 to 2009 Canadian Health Measures Survey. Ottawa: Statistics Canada; 2011.

5. Colley RC, Garriguet D, Janssen I, et al. Physical activity of Canadian adults: accelerometer results from the 2007 to 2009 Canadian Health Measures Survey. Ottawa: Statistics Canada; 2011.

6. Mowat D, Gardner C, McKeown D, et al. Improving health by desion in the Greater Toronto-Hamilton Area. a report of Medical Officers of Health in the GTHA. Medical Officers of Health in the GTHA; 2014. Available: www.peelregion.ca/ health/resources/healthbydesign/pdf/moh-report.pdf (accessed 2016 Nov. 3).

7. Healthy places. Atlanta: Centers for Disease Control and Prevention; 2015. Available: www.cdc.gov/healthyplaces/ (accessed 2016 Mar. 8).

8. Riley DL, Mark AE, Kristjansson E, et al. Neighbourhood walkability and physical activity among family members of people with heart disease who participated in a randomized controlled trial of a behavioural risk reduction intervention. Health Place 2013;21:148-55.

9. McGrath LJ, Hopkins WG, Hinckson EA. Associations of objectively measured built-environment attributes with youth moderate-vigorous physical activity: a systematic review and meta-analysis. Sports Med 2015;45:841-65. 
10. Sundquist K, Eriksson U, Kawakami N, et al. Neighborhood walkability, physical activity, and walking behavior: The Swedish Neighborhood and Physical Activity (SNAP) study. Soc Sci Med 2011;72:1266-73.

11. Cohen DA. Obesity and the built environment: changes in environmental cues cause energy imbalances. Int 7 Obes (Lond) 2008;32:S137-S142.

12. Janssen I, Leblanc AG. Systematic review of the health benefits of physical activity and fitness in school-aged children and youth. Int 7 Bebav Nutr Phys Act 2010;7:40.

13. Warburton DER, Nicol CW, Bredin SSD. Health benefits of physical activity: the evidence. CMA7 2006;174:801-9.

14. McCormack GR, Shiell A. In search of causality: a systematic review of the relationship between the built environment and physical activity behaviour. Int 7 Behav Nutr Phys Act 2011;8:125.

15. Ding D, Sallis JF, Kerr J, et al. Neighborhood environment and physical activity among youth: a review. Am 7 Prev Med 2011;41:442-55.

16. Ainsworth BE, Haskell WL, Herrmann SD, et al. 2011 Compendium of Physical Activities: a second update of codes and MET values. Med Sci Sports Exerc 2011;43:1575-81

17. Wong SL, Colley R, Connor Gorber S, et al. Actical accelerometer sedentary activity thresholds for adults. 7 Phys Act Health 2011;8:587-91.

18. King WC, Chen J-Y, Courcoulas AP, et al. Objectively-measured sedentary time and cardiometabolic health in adults with severe obesity. Prev Med 2016;84:12-8.

19. Koohsari MJ, Sugiyama T, Sahlqvist S, et al. Neighborhood environmental attributes and adults' sedentary behaviors: Rrview and research agenda. Prev Med 2015;77:141-9.

20. Van Cauwenberg J, De Bourdeaudhuij I, De Meester F, et al. Relationship between the physical environment and physical activity in older adults: a systematic review. Health Place 2011;17:458-69.

21. Sugiyama T, Neuhaus M, Cole R, et al. Destination and route attributes associated with adults' walking: A review. Med Sci Sports Exerc 2012;44:1275-86.

22. Canadian bealth measures survey data user guide: cycle 1. Ottawa: Statistics Canada; 2011. Available: www23.statcan.gc.ca/imdb-bmdi/document/5071_D2_T1_ V1-eng.htm\#a5_3_2_2 (accessed 2016 Mar. 3).

23. Canadian Health Measures Survey (CHMS). Detailed information for August 2009 to November 2011 (cycle 2). Ottawa: Statistics Canada; 2012. Available: www23. statcan.gc.ca/imdb/p2SV.pl? Function=getSurvey\&Id=62444\#a4 (accessed 2016 Mar. 3).

24. Urban area (UA). Ottawa: Statistics Canada; 2009. Available: www12.statcan. gc.ca/census-recensement/2006/ref/dict/geo049-eng.cfm (accessed 2016 Mar. 8).

25. Walk Score Methodology. 2012. Available: www.walkscore.com/methodology .shtml (accessed 2016 Mar. 8)

26. Duncan DT, Aldstadt J, Whalen J, et al. Validation of Walk Score for estimating neighborhood walkability: an analysis of four US metropolitan areas. Int 7 Environ Res Public Health 2011;8:4160-79.

27. Carr LJ, Dunsiger SI, Marcus BH. Walk Score ${ }^{\mathrm{TM}}$ as a global estimate of neighborhood walkability. Am 7 Prev Med 2010;39:460-3.

28. Carr LJ, Dunsiger SI, Marcus BH. Validation of Walk Score for estimating access to walkable amenities. Br 7 Sports Med 2011;45:1144-8.

29. Chiu M, Shah BR, Maclagan LC, et al. Walk Score ${ }^{\circledR}$ and the prevalence of utilitarian walking and obesity among Ontario adults: a cross-sectional study. Health Rep 2015;26:3-10.

30. Chiu M, Rezai M-R, Maclagan LC, et al. Moving to a highly walkable neighborhood and incidence of hypertension: a propensity-score matched cohort study. Environ Health Perspect 2016;124:754-60.

31. Thielman J, Rosella L, Copes R, et al. Neighborhood walkability: differential associations with self-reported transport walking and leisure-time physical activity in Canadian towns and cities of all sizes. Prev Med 2015;77:174-80.

32. Dissemination area (DA) - Census Dictionary. Ottawa: Statistics Canada; 2012. Cat no 98-301-XWE. Available: www12.statcan.gc.ca/census-recensement/ 2011/ref/dict/geo021-eng.cfm (accessed 2016 July 3).

33. Postal Code ${ }^{O M}$ Conversion File (PCCF), reference guide, 2013. Ottawa: Statistics Canada; 2013. Cat no 92-154-G. Available: www5.statcan.gc.ca/olc-cel/olc.action ?ObjId=92-154-G\&ObjType=2\&lang=en $\&$ limit=0 (accessed 2016 Mar. 8).

34. Colley RC, Tremblay MS. Moderate and vigorous physical activity intensity cut-points for the Actical accelerometer. 7 Sports Sci 2011;29:783-9.

35. Puyau MR, Adolph AL, Vohra FA, et al. Prediction of activity energy expenditure using accelerometers in children. Med Sci Sports Exerc 2004:36:1625-31.

36. Canadian Health Measures Survey (CHMS) cycle 1 wave 4 derived variable (DV) specifications. Ottawa: Statistics Canada. Available: www23.statcan.gc.ca/ imdb/pIX.pl?Function=showStaticArchiveHTML\&fl=http://www23.statcan.gc. ca/imdb-bmdi/document/5071_D3_T9_V5-eng.htm\&Item_Id=95435 (accessed 2016 Mar. 3).

37. Seliske L, Pickett W, Janssen I. Urban sprawl and its relationship with active transportation, physical activity and obesity in Canadian youth. Health Rep 2012;23:17-25

38. Butler GP, Orpana HM, Wiens AJ. By your own two feet: factors associated with active transportation in Canada. Can f Public Health 2007;98:259-64.

39. Adamo KB, Langlois KA, Brett KE, et al. Young children and parental physical activity levels: findings from the Canadian Health Measures Survey. Am $\mathcal{F}$ Prev Med 2012;43:168-75.
40. Ross NA, Tremblay SS, Graham K. Neighbourhood influences on health in Montréal, Canada. Soc Sci Med 2004;59:1485-94.

41. Giles-Corti B, Donovan RJ. Socioeconomic status differences in recreational physical activity levels and real and perceived access to a supportive physical environment. Prev Med 2002;35:601-11.

42. King KE, Clarke PJ. A disadvantaged advantage in walkability: findings from socioeconomic and geographical analysis of national built environment data in the United States. Am 7 Epidemiol 2015;181:17-25.

43. Glazier RH, Creatore MI, Weyman JT, et al. Density, destinations or both? A comparison of measures of walkability in relation to transportation behaviors, obesity and diabetes in Toronto, Canada [published erratum in PLoS One 2014;9:e91485] PLoS One 2014;9:e85295.

44. Prince SA, Adamo KB, Hamel ME, et al. A comparison of direct versus selfreport measures for assessing physical activity in adults: a systematic review. Int 7 Behav Nutr Phys Act 2008;5:56.

45. Hajna S, Ross NA, Brazeau A-S, et al. Associations between neighbourhood walkability and daily steps in adults: a systematic review and meta-analysis. BMC Public Health 2015;15:768.

46. Sallis JF, Saelens BE, Frank LD, et al. Neighborhood built environment and income: examining multiple health outcomes. Soc Sci Med 2009;68:1285-93.

47. Carlson JA, Sallis JF, Conway TL, et al. Interactions between psychosocial and built environment factors in explaining older adults' physical activity. Prev Med 2012;54:68-73.

48. Norman GJ, Nutter SK, Ryan S, et al. Community design and access to recreational facilities as correlates of adolescent physical activity and body-mass index. 7 Phys Act Health 2006;3:S118-28.

49. Hajna S, Ross NA, Joseph L, et al. Neighbourhood walkability, daily steps and utilitarian walking in Canadian adults. BM7 Open 2015;5:e08964.

50. Shibata A, Oka K, Sugiyama T, et al. Perceived neighbourhood environmental attributes and prospective changes in TV viewing time among older Australian adults. Int 7 Behav Nutr Phys Act 2015;12:50.

51. Smith NR, Lewis DJ, Fahy A, et al. Individual socio-demographic factors and perceptions of the environment as determinants of inequalities in adolescent physical and psychological health: the Olympic Regeneration in East London (ORiEL) study. BMC Public Health 2015;15:150

52. Richard JR. The impact of the built environment on health: an emerging field. Am F Public Health 2003;93:1382-4.

Affiliations: Public Health Ontario (Thielman, Manson, Copes, Rosella); Dalla Lana School of Public Health (Manson, Chiu, Copes, Rosella), University of Toronto; Institute for Clinical Evaluative Sciences, (Chiu) Toronto, Ont

Contributors: All of the authors contributed to conceptualizing and designing the study, planning analytical methods, and analyzing and interpreting statistical output. Justin Thielman conducted the literature review and statistical analysis, and drafted the manuscript. All of the authors reviewed the manuscript critically for intellectual content, approved the final version to be published and agreed to act as guarantors of the work.

Funding: Financial support for this study was provided to all authors by Public Health Ontario through an annual peer-reviewed competitive Project Initiation Fund (2013-14-019). The opinions, results and conclusions reported in this paper are those of the authors and are independent from the funding source. The study sponsor had no role in the study design; collection, analysis, or interpretation of data; report writing or review; approval of the manuscript; or the decision to submit for publication.

Acknowledgements: Statistics Canada's Research Data Centre Program made the Canadian Health Measures Survey data available and provided support for working with these data. Walk Score provided the walkability data and related support.

Supplemental information: For reviewer comments and the original submission of this manuscript, please see www.cmajopen.ca/content/4/4/ E720/suppl/DC1

Disclaimer: This study was supported by the Institute for Clinical Evaluative Sciences (ICES), which is funded by an annual grant from the Ontario Ministry of Health and Long-Term Care (MOHLTC). The opinions, results and conclusions reported in this article are those of the authors and are independent from the funding sources. No endorsement by ICES or the Ontario MOHLTC is intented or should be inferred. The research and analysis are based on data from Statistics Canada, and the opinions expressed do not represent the views of Statistics Canada. 